\section{Assessment of Biometal Profile in Children with Autism Spectrum Disorder, with Attention Deficit Hyperactivity Disorder, or with Other Psychiatric Diagnoses: A Comparative Outpatient Study}

\section{Abstract}

Background: In recent years, the impact of various micronutrients on the symptoms of ADHD and ASD has been studied. Our study was aimed at evaluating the association between the level of serum magnesium, zinc and ferritin in children diagnosed with ADHD and/or ASD.

Methods: This case-control pilot study consisted of 32 children who met DSM-V criteria for ADHD, 15 children who met DSM-V criteria for ASD and 12 age-matched control children from Electronic Medical Record database. Serum magnesium, zinc and ferritin values were com-pared with ANOVA.

Results: Blood ferritin level was found to be significantly lower in affected groups $(F=5.9, p=0.0056)$. A trend towards decreased values of plasma zinc level was also found in affected children $(F=2.25, p=0.12)$; whereas no suggestion of any difference in blood magnesium levels between three groups was significant. Non-parametric analyses were also run and the $p$ value for ferritin 0.08 , showed weaker evidence of significance.

Conclusions: Results of this study indicated that low level of blood ferritin may be a risk factor for development of ASD and ADHD. Future investigations with larger controlled trials are needed and correlational studies would also be helpful.

Keywords: ADHD; Autism; Magnesium; Zinc; Ferritin

Received: February 01, 2018; Accepted: February 12, 2018; Published: February 26, 2018

\section{Introduction}

Attention Deficit Hyperactivity Disorder (ADHD) is one of the most common neuropsychiatric disorders that affects $8-12 \%$ of children worldwide $[1,2]$. ADHD is characterized by consistent and age-inappropriate levels of inattention, impulsivity and/ or hyperactivity [3]. Although the pathophysiology of ADHD is complex and not clearly understood [4,5], several lines of evidence suggest a relevance of the dopaminergic and noradrenergic systems in the cause of ADHD [6,7].

Many studies using different methodologies have indicated that dopamine is a key element of ADHD pathophysiology. Some authors suggested that the lack of efficient dopaminergic control
Murat Pakyurek ${ }^{1 *}$, Atoosa Azarang ${ }^{2}$, Ana-Maria losif ${ }^{3}$ and Thomas E Nordahl ${ }^{1}$

1 Department of Psychiatry and Behavioral Sciences, University of California-Davis, School of Medicine, Sacramento, USA

2 M.I.N.D. Institute, University of California-Davis Medical Center, Sacramento, USA

3 Department of Public Health Sciences, University of California-Davis, School of Medicine, USA

\section{*Corresponding author: Murat Pakyurek \\ ほmpakyurek@ucdavis.edu}

Clinical Professor of Psychiatry and Behavioral Sciences, University of California, Davis Medical Center, 2230 Stockton Blvd. School of Medicine, Sacramento, CA 95817, USA.

Tel: +1916 734-3574

Fax: $+916734-0849$

Citation: Pakyurek M, Azarang A, losif AM, Nordahl TE (2018) Assessment of Biometal Profile in Children with Autism Spectrum Disorder, with Attention Deficit Hyperactivity Disorder, or with Other Psychiatric Diagnoses: A Comparative Outpatient Study. Acta Psychopathol Vol.4 No.1:6 
for the degradation of dopamine [14]. All of these results suggest that iron metabolism may have important role in ADHD pathophysiology. Ferritin is a marker of peripheral iron supplies and can be used to estimate body-iron stores [15]; however, it is not known if it reflects brain iron levels, but some studies have shown lower levels of ferritin in children with ADHD, other studies have not found this correlation; therefore, current results are mixed [16-19].

Dietary deficiencies of zinc and magnesium are also suspected to be associated with mild to significant changes in neuronal function, which can lead to poor health and adverse effects on behavior and learning [20]. Several researchers reported a link between zinc levels and ADHD symptoms [21]. Although the exact mechanism of how zinc may contribute to symptoms of ADHD is not known, there is evidence that zinc assists in both the production and regulation of melatonin, which is an important factor in the pathophysiology of ADHD due to its modulation of dopamine. Zinc also binds to and regulates the dopamine transporter, which is a site of action of psychostimulants used to treat ADHD [22].

Magnesium acts as an ionic membrane regulator and modulator of ion transfer through membrane channels. In animal studies, Magnesium has been shown to interact with the serotonergic, noradrenergic, and dopaminergic systems [23]. Magnesium also activates tyrosine hydroxylase, the rate-limiting step in dopamine synthesis and it binds serotonin and dopamine to their receptors [24].

Autism Spectrum Disorder (ASD), on the other hand, is a multifactorial disorder characterized by deficit in social communication and interactions as well as restrictive and repetitive patterns of behavior [3]. The pathophysiological etiologies which precipitate autism symptoms remain elusive and controversial in many cases, but both genetic and environmental factors (and their interactions) have been implicated [25].

Previous studies have raised concerns that intake of iron, B vitamins, vitamin $D$, magnesium, calcium, and zinc may be deficient in up to one-third of children with ASD, and that dietary insufficiency may be more common in children on a restrictive diet [26-29]. Studies show that children with autism are at higher risk for iron deficiency and this condition may increase the severity of psychomotor and behavioural problems [30].

Another important element of cell signalling is zinc, which is involved in glutamatergic transmission [31]. There are also some observations from patients with fragile $X$ syndrome suggesting that interactions between zinc and glutamate may exist [32]. It is conceivable that zinc after being absorbed by the postsynaptic neuron can act as an important trophic factor, i.e. as a nutrient that can later be involved in permanent learning processes [33].

Some studies show that zinc levels in the plasma, hair, and nails of patients with ASD may be abnormal [34,35]. Low intracellular zinc has been associated with DNA damage, which might be due to a combination of oxidative stress, impairment of anti-oxidant defenses and impairment of DNA repair. Zinc deficiency occurs not only as a result of abnormal nutritional intake, but also due to various disease states, including malabsorption and immune dysregulation syndromes [36]. Changes in the intestinal flora and function are common in autistic patients $[37,38]$; it is therefore conceivable that malabsorption due to pathological changes in the intestinal mucosa may play an important role as one of the causes of zinc deficiency in autism. Magnesium plays an essential role in brain development and functional well-being, through activation of cop-per-zinc superoxide dismutase (CUZn-SOD) and nitric oxide release from cells [39]. Chronic low blood levels of Magnesium might lead to growth retardation and behavioural changes [40]. Magnesium in conjunction with vitamin B6, has been proposed for many years as a nutritional factor in the treatment of autism $[41,42]$.

The aim of the present study was to test whether blood levels of zinc, magnesium and ferritin are altered in children with ADHD and/or ASD compared to healthy control subjects. We hypothesize that blood levels of ferritin and zinc will be abnormal in both ADHD and/or ASD children.

\section{Methods}

Our retrospective chart review study included 32 children with ADHD (aged 5-18 years, mean:10.53, SD:2.86, 84.37\% boys, $15.63 \%$ girls) and 15 children with ASD (aged 5-18 years, mean:13.67, SD: $3.46,80 \%$ boys, $20 \%$ girls) were collected through Electronic Medical Record (EMR) database from University of California, Davis (UCD), medical centre from 2015 to pre-sent (Figure 1). The diagnoses were made after a series of structured interviews were conducted by a psychologist and one Child

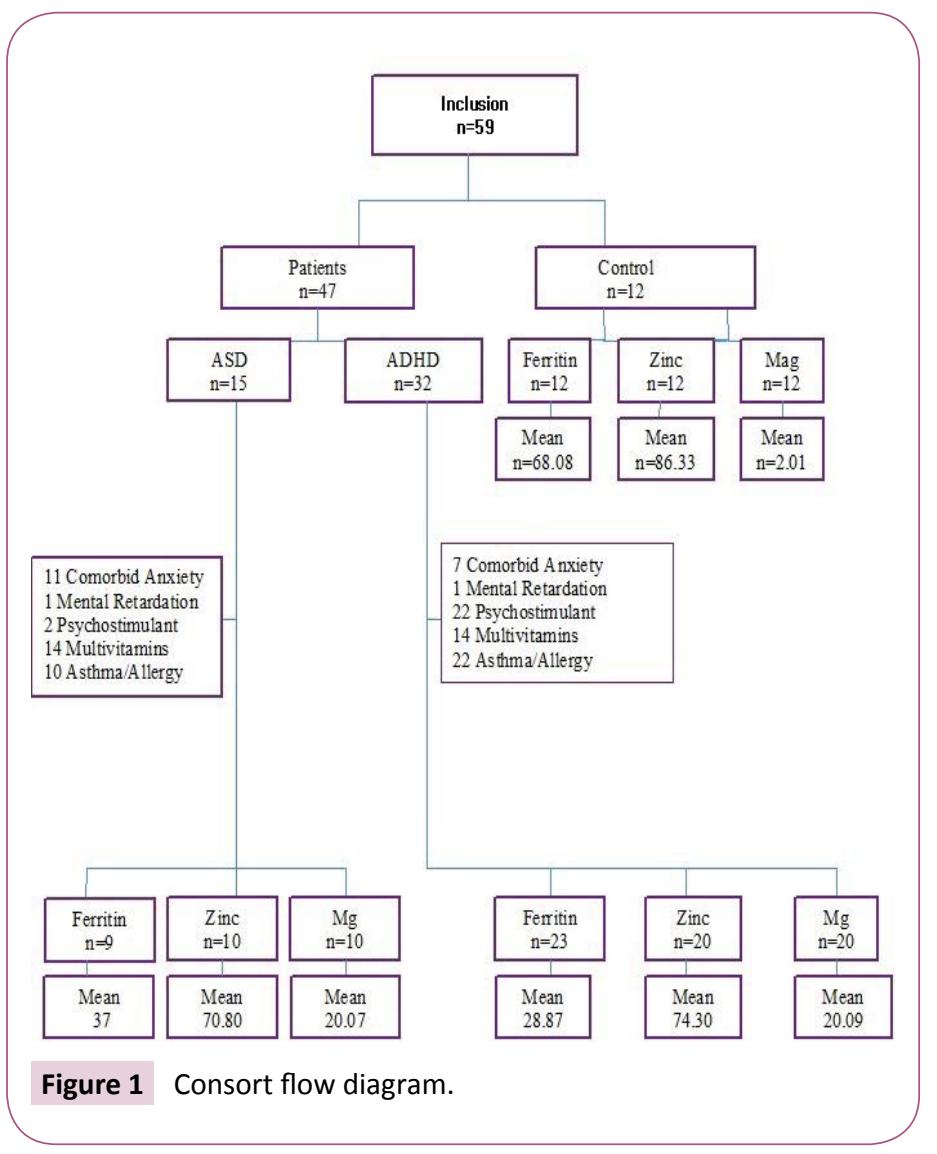


and Adolescent psychiatrist at UCD, Child and Adolescent clinic based on the criteria for ADHD and ASD defined in the Diagnostic and Statistical Manual of Mental Disorders [3], 5th Edition. All procedures were approved by the Institutional Review Board of UCD (No. 999488-1).

Seven cases of ADHD children and eleven cases of ASD children had comorbid anxiety disorder, one case of ADHD children and one case of ASD children had mental retardation. Twenty-five ADHD children and two ASD children were treated with psycho stimulant medications, fourteen children of both categories had nutritional supplements within the last six months and twentytwo children had asthma/allergy history. Twenty-one of the ADHD children met the criteria for combined, eight for inattentive, two for hyperactive-impulsive and one for ADHD-NOS subtype.

The typically-developing (TD) controls included 12 ages, gender and socioeconomic matched control children (mean: 13.50, SD: 2.35) recruited from UCD Psychiatry Department. The TD children had no abnormal histories of motor, language, or social developmental disorders, as deter-mined according to the reports of the parents and teachers.

Ferritin, zinc and magnesium data were collected from each patient review chart via the EMR system. The manufacturerdefined deficiency levels for ferritin, zinc and magnesium were lower than $22 \mathrm{ng} / \mathrm{ml}, 55 \mathrm{mc} / \mathrm{dl}$ and $1.5 \mathrm{mg} / \mathrm{dl}$ for both male and females respectively. Values are given as mean $\pm \mathrm{SD}$. A one-way analysis of variance (ANOVA) is used to determine whether there are any statistically significant differences between the means of zinc, magnesium and ferritin among ASD and ADHD groups. However, since the variability is not homogeneous across groups, non-parametric tests such as Tukey-Kramer method and PROC LOGISTIC in SAS Version 9.4 were used for ferritin analysis.

\section{Results}

Blood ferritin level was $28.87 \pm 12.27 \mathrm{mg} / \mathrm{dl}$ in ADHD group (71.8\%), $37 \pm 19.25 \mathrm{mg} / \mathrm{dl}$ in ASD group (60\%) and $68.08 \pm 57.65$ $\mathrm{mg} / \mathrm{dl}$ in controls. Ferritin was significantly lower in both affected groups $(F=5.9, p=0.0056)$ with weaker association for ASD vs control (Table 1 and Figure 2).

Blood magnesium level was $2.09 \pm 0.11 \mathrm{mg} / \mathrm{dl}$ in ADHD group, $2.07 \pm 0.24 \mathrm{mg} / \mathrm{dl}$ in ASD group and in control it was $2.01 \pm$ $0.36 \mathrm{mg} / \mathrm{dl}$, with no significant difference between both groups ( $F=0.46, p=0.6361 ;$ Table 1).

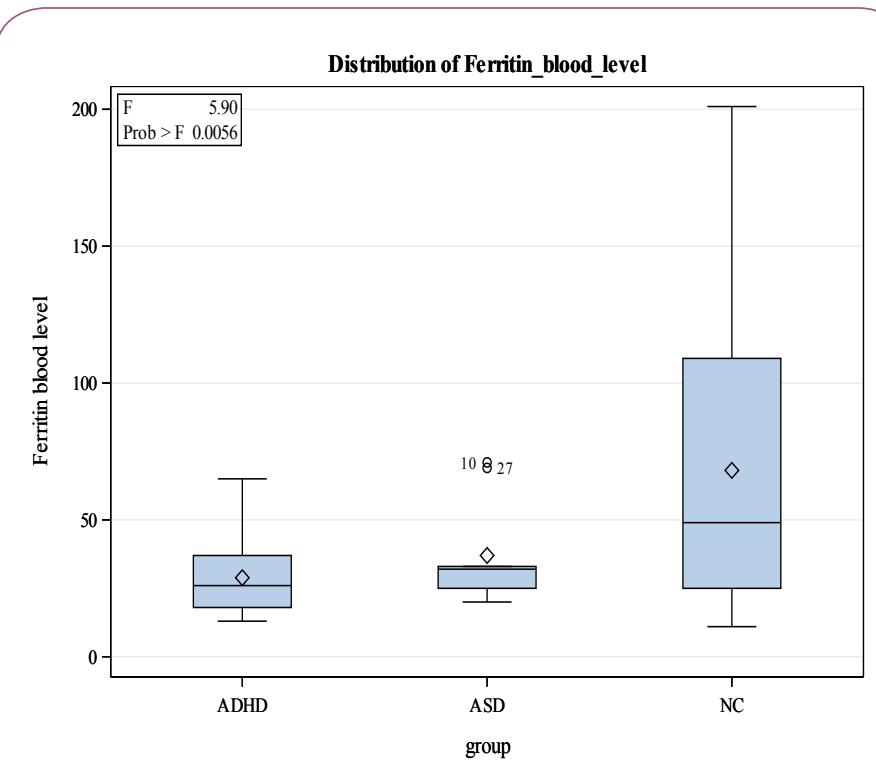

Figure 2 Distribution of ferritin blood level in children with ADHD/ ASD and control.

A trend towards decreased values of plasma zinc level was also found in affected children $(74.30 \pm 11.96 \mu \mathrm{g} / \mathrm{dl}$ in ADHD group, $70.80 \pm 12.39 \mu \mathrm{g} / \mathrm{dl}$ in ASD group and $29.46 \pm 58 \mu \mathrm{g} / \mathrm{dl}$ in control; (Table 1 and Figure 3). The overall group difference for Tukey kramer method was weaker than Standard GLM method; however, it was still statistically significant for ferritin compare with zinc and magnesium.

\section{Discussion}

In the current study, it has been demonstrated that $71.8 \%$ of children with ADHD have low blood ferritin level. These findings are in parallel with previous studies by Ozgur, [2] who reported that lower ferritin level was associated with higher hyperactivity scores in parental ratings of children with ADHD. As previously reported by Konofal et al. [43] significantly lower serum ferritin levels have been observed in children with ADHD than in controls Indeed, $84 \%$ of children had serum ferritin levels of less than $30 \mathrm{ng} / \mathrm{mL}$, compared to $18 \%$ of controls $(\mathrm{P}<0.001)$. In another study, Oner et al. [2] found a significant correlation between serum ferritin levels and Conners Parent Rating Scale (CPRS) hyperactivity score in 52 children with ADHD ( $p=0.02)$. Oner et al. [8] recently reported a significant inverse correlation between serum ferritin levels and CPRS hyperactivity score; however, they

Table 1 Different trace elements levels in children with ADHD/ ASD and in the control group.

\begin{tabular}{|c|c|c|c|c|c|c|c|c|}
\hline Group & $\mathbf{N}$ & Variable & Label & $\mathbf{N}$ & Mean & Standard deviation & Minimum & Maximum \\
\hline ADHD & 32 & $\begin{array}{c}\text { Mg blood level } \\
\text { Zinc blood level } \\
\text { Ferritin blood level }\end{array}$ & $\begin{array}{c}\text { Mg blood level } \\
\text { Zinc blood level } \\
\text { Ferritin blood level }\end{array}$ & $\begin{array}{l}20 \\
20 \\
23\end{array}$ & $\begin{array}{c}2.09 \\
74.30 \\
28.87\end{array}$ & $\begin{array}{c}0.11 \\
11.96 \\
12.27\end{array}$ & $\begin{array}{c}1.80 \\
51.00 \\
13.00\end{array}$ & $\begin{array}{c}2.20 \\
90.00 \\
65.00\end{array}$ \\
\hline ASD & 15 & $\begin{array}{l}\text { Mg blood level } \\
\text { Zinc blood level } \\
\text { Ferritin blood level }\end{array}$ & $\begin{array}{c}\text { Mg blood level } \\
\text { Zinc blood level } \\
\text { Ferritin blood level }\end{array}$ & $\begin{array}{c}10 \\
10 \\
9\end{array}$ & $\begin{array}{c}2.07 \\
70.80 \\
37.00\end{array}$ & $\begin{array}{c}0.24 \\
12.39 \\
19.25\end{array}$ & $\begin{array}{c}1.90 \\
51.00 \\
20.00\end{array}$ & $\begin{array}{c}2.70 \\
88.00 \\
71.00\end{array}$ \\
\hline NC & 12 & $\begin{array}{l}\text { Mg blood level } \\
\text { Zinc blood level } \\
\text { Ferritin blood level }\end{array}$ & $\begin{array}{c}\text { Mg blood level } \\
\text { Zinc blood level } \\
\text { Ferritin blood level }\end{array}$ & $\begin{array}{l}12 \\
12 \\
12\end{array}$ & $\begin{array}{c}2.01 \\
86.33 \\
68.08\end{array}$ & $\begin{array}{c}0.36 \\
29.46 \\
57.65\end{array}$ & $\begin{array}{c}1.60 \\
58.00 \\
11.00\end{array}$ & $\begin{array}{c}2.50 \\
144.00 \\
201.00\end{array}$ \\
\hline
\end{tabular}




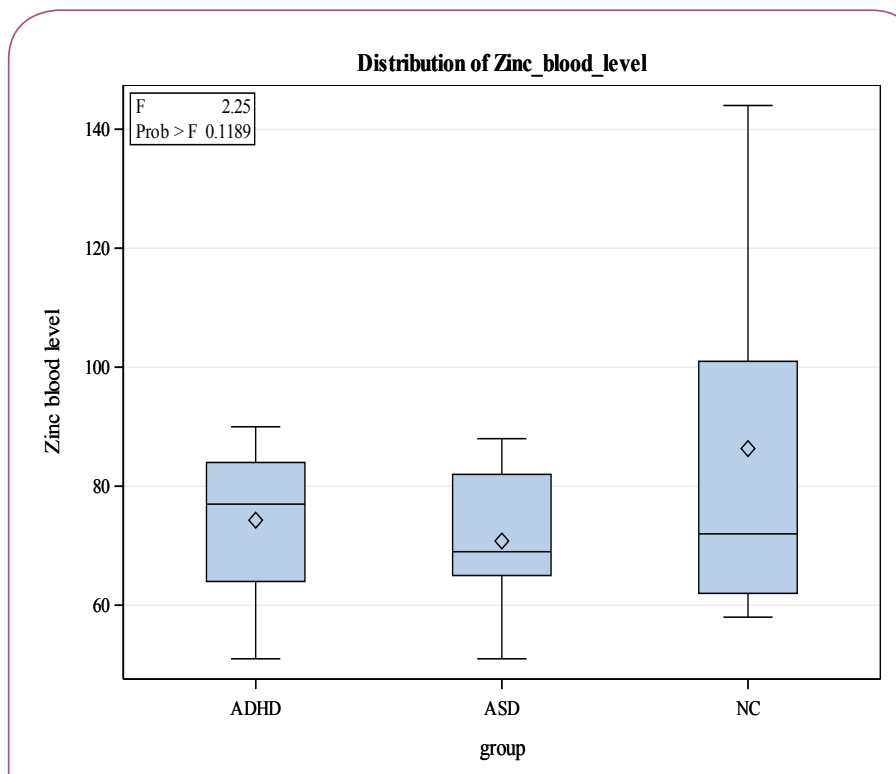

Figure 3 Distribution of zinc blood level in children with ADHD/ASD and control.

could not confirm a significant correlation with other CPRS sub scale scores or with any score at the Conners Teacher Rating Scale (CTRS).

On the other hand, several studies failed to find empirical support for a possible peripheral iron deficiency in ADHD. Chen et al. [44] published a study assessing dietary patterns and serum trace minerals in a sample from Taiwan, and found that serum iron was significantly higher in the ADHD group $(19.7 \pm 6.4 \mu \mathrm{mol} / \mathrm{l})$ vs. comparisons $(16.1 \pm 6.4 \mu \mathrm{mol} / \mathrm{l} ; \mathrm{p}<0.05)$ Subsequently, in a non-controlled study, Millichap, et al. [15] reported no significant difference between serum ferritin level measured in 68 children with $A D H D$ in relation to national norms. In a sample of 41 children with ADHD and 21 comparisons, Menegassi, et al. [7] found no significant intergroup differences as well. A study by Kiddie and colleges [45] also failed to find significant differences between serum ferritin levels of 44 children with ADHD in relation to national population norms.

Although in our study the number of children with ASD was relatively low, our findings showed a decreased mean level of ferritin among these patients (ASD, mean ferritin level: 37, SD: 19.25 vs. Control, mean ferritin level: 68.08, SD: 57.65; $F=5.9$, $\mathrm{P}=0.0056)$. This finding supports previous studies from South Wales, Turkey, and Canada, that reported higher rates of iron deficiency/low serum ferritin (7\% to $52 \%$ ) in children with ASD than in the general population [46]. In another study, Hergüner et al. [47] found anemia in $1 \%$ to $15 \%$ of children with ASDs. Study in the UK examining iron deficiency anemia in children with autism and Asperger syndrome found $52 \%$ of children with autism to be iron-deficient compared with $13.6 \%$ of children with Asperger syndrome [48]. ASD has been found to produce picky eating, resistance to new foods, preference for limited food groups, resistance to sitting at the table, and abnormal, aggressive feeding behaviors [49]. This supports the reported high prevalence of iron deficiency and malnutrition in this population subset. Identifying iron deficiency when present is important, because iron deficiency, even without anemia, has adverse consequences on developmental and behavioural function in infants and children [50].

In our study, a trend towards decreased values of plasma zinc level was found in both ASD and ADHD children and the decrease value were more significant in ADHD than ASD group. Several researchers suggest that zinc supplementation might be effective in decreasing ADHD symptoms. Uçkardeş et al. [51] showed that the mean Conner's Rating Scale for Parents scores on attention deficit, hyperactivity, oppositional behavior and conduct disorder decreased significantly in the study and placebo groups after supplementation $(p<0.01)$.

Among individuals with ASD, the incidence of zinc deficiency has been reported to be significantly abnormal compared to age matched healthy control subjects [34,52]. Lakshmi and Geetha [53] found that the level of zinc in autistic children could be correlated with the severity of their symptoms. The children in the low functioning autism group showed lower levels of zinc in both hair and nail samples when compared to middle and high functioning autism (Mean concentration of zinc in the nail samples of 50 control:193.98 $\pm 23.27,15$ Low Functioning Autism: 150.83 $\pm 18.09 \mathrm{p}<0.01,15$ Middle Functioning Autism:192.02 \pm 23.04 and15 High Functioning Autism:187.44 $\pm 22.47 p<0.01$. mean concentration of zinc in the hair samples of 50 control: 171.68 \pm 20.60 , 15 Low Functioning Autism: $130.46 \pm 15.65$ p<0.01, 15 Middle Functioning Autism:172.81 $\pm 20.73,15$ High Functioning Autism:171.92 \pm 20.63 . The occurrence of zinc deficiencies in ASD is particularly pronounced in the very young age, where a rate of almost $50 \%$ was reported in the age group of $0-3$ years $[54,55]$.

Zinc has been found to modulate several types of receptors including glutamatergic, GABAergic, dopaminergic, serotonergic and nicotinic receptors [56] in different parts of the brain including striatum. The striatum is involved in the modulation of fine motor skills, goal-directed learning, habit formation, and in motivation and reward processes [57]. Most input to the striatum is glutamatergic. Importantly, the striatum also receives dopaminergic input from the substantia nigra and ventral tegmental area $[58,59]$. Striatal dopamine innervation plays a role in striatal plasticity [60]. Alterations in striatal dopamine levels lead to disorders that can have both motor and cognitive dysfunction such as ASD [61] and ADHD [62].

It is of special interest for the striatum that zinc binding sites have been found on dopamine receptors [63], suggesting that zinc may have a modulatory role on the dopaminergic system. As noted above, glutamate is the main neurotransmitter input to the striatum; in particular, striatal input from cortex uses glutamate as its main neurotransmitter [59]. Synaptic zinc binding level has strong ties to the glutamatergic system and can modulate all three kinds of glutamate receptors [64,56]. Since synaptic zinc binding level is capable of modulating both groups of receptors, it is likely that it is doing so in the striatum and that alterations of synaptic zinc levels may affect functioning of both neurotransmitter systems [64]. 
Further, zinc is necessary for vitamin B6 to be metabolized to its active form, pyridoxal phos-phate, which in turn plays a role in conversion of tryptophan to serotonin $[35,65,66]$. Serotonin (5-Hydroxytryptophan, 5-HTP) signalling is not only important in the brain, but also in the GI tract [67]. 5-HTP is released from gut enterochromaffin cells and might contribute to 5-HTP signalling in the brain. However, the gut and the brain are not the only sites of action for 5-HTP. Its receptors are also present in the immune system where 5-HTP signalling may mediate both innate and adaptive responses [68].

Research strongly suggests that zinc might play a role in modulating GABAergic inhibition and seizure susceptibility [69]. It has been suggested that low zinc level may modulate GABA synthesis, ultimately causing a lowering of transmitter concentration in the synaptic cleft [36]. GABA is synthesized by the enzyme glutamate decarboxylase using pyridoxal phosphate as a cofactor [70]. Glutamate decarboxylase plays a very important role in maintaining excitatory-inhibitory balance of the central nervous system [71].

In this present study, there was not a statistical difference of serum magnesium level between the control and both ADHD and ASD groups. In a sample of 76 children in France, compared to healthy controls, those with ADHD had lower RBC magnesium levels but serum magnesium lev-el was normal in the control and ADHD group [45]. Mousain-Bosc et al. [72] found no changes in serum magnesium level between the control and ADHD group Ac-cording to a study done in Poland, children with ADHD had lower levels of magnesium com-pared to healthy controls. Percentage of magnesium deficiency was dependent on method of measurement: $33.6 \%$ were deficient on serum magnesium, $77.6 \%$ on hair, and $58.6 \%$ on red blood cell magnesium level [73]. Conversely, a group of college students diagnosed with ADHD in the United States, when compared to healthy controls, had higher levels of serum magnesium (789.35 \pm 127.22 uM vs. $630.67 \pm 87.28 \mathrm{uM}, \mathrm{p}=0.002$ ) but when RBC magnesium levels were compared, they were no differences be-tween groups [74]. Determination of magnesium status is complicated by the fact that its concentration in extracellular space is four times less than intracellular space. In fact, only $1 \%$ of magnesium is extracellular [75]. Furthermore, plasma/serum levels of magnesium are tightly regulated; one-third of magnesium in bone is freely exchanged with the plasma; therefore, even if intake is inadequate, normal serum levels may be maintained by bone stores. Some researchers believe that blood plasma/serum magnesium do not precisely reflect intracellular level of magnesium and this may be better reflected in RBC-magnesium levels [24], but it is unknown whether serum/plasma magnesium or RBC-magnesium reflects intracerebral magnesium levels. The level of magnesium in plasma is lower than cerebrospinal gradient in which an active transport process maintains this gradient. Phosphorus Nuclear Magnetic Resonance (NMR) Spectroscopy is suggested for assessment of magnesium in the brain [24,75].

Some studies, in which the aim was to assess plasma and erythrocyte concentrations of magnesium in ASD and control subjects, did not find significant differences in intracellular magnesium between groups but found significant decrease in plasma magnesium level in patients with ASD [42]. Mousain-
Bosc et al. [76] reported that thirty-three children with clinical symptoms of ASD exhibit significantly lower red blood cell magnesium values, and that the combination therapy with magnesium/vitamin B6 for 6 months improved ASD symptoms in $23 / 33$ children $(p<0.0001)$ with concomitant increases in intraerythrocyte magnesium values.

\section{Strengths and Limitations}

To our knowledge this is the first study to investigate blood levels of ferritin, zinc and magnesium in children with ADHD and/or ASD. Indeed, the association of both iron and zinc metabolisms and ADHD/ASD symptoms in a single sample has not been investigated before; however, our study has limitations. First, and foremost, the sample size was relatively small. Therefore, the present results should be confirmed in a larger-scale prospective cohort study.

Second, we did not exclude patients who received treatment with psychostimulants in our study. In a study by D'Amato [77], it has been pointed out that psycho stimulants may affect appetite and, consequently, alter serum ferritin levels Although in the study by Millichap [15] the authors did not find any significant association between serum ferritin levels and response to psychostimulant treatment. In the largest controlled study contrasting serum ferritin levels in psychostimulant-naive children with ADHD $(n=101)$ and matched comparisons $(n=93)$, Donfrancesco et al. [78] did not find a significant difference in serum ferritin levels. Moreover, relationships of serum ferritin to ADHD types, IQ and ADHD severity were not significant as well. Serum ferritin is an acute phase reactant and elevated in the face of inflammation. Inflammation would artificially increase the ferritin levels and decrease suspicion of iron deficiency. The use of both serum ferritin and transferrin saturation needs to be included because of the lack of sensitivity or specificity for each test alone.

We didn't exclude children who had received supplementation. Fourteen children of both categories had nutritional supplements within the last six months. Also, it is not clear if the nutritional supplements include iron and zinc. Gender difference, ADHD subtype and presence of psychiatric comorbidity was not excluded either. We don't know if zinc or ferritin supplement can improve ADHD total score or has any effect on inattentiveness/ hyperactivity score separately. In a study by Oner P. et al. [8] serum ferritin level was not significantly associated with gender, ADHD subtype, or presence of comorbid disorders ADHD subtypes may have impact on blood magnesium level. In an Egyptian sample, compared to healthy controls, serum magnesium levels were lower in children with hyperactive and combined type ADHD $(2.2 \pm 0.9 \mathrm{meq} / \mathrm{L}$ vs. $1.7 \pm 0.8 \mathrm{meq} / \mathrm{L}, \mathrm{p}=0.02)$ and there were no differences in serum magnesium level in the subgroup of children with ADHD-inattentive type. Meanwhile, stimulants may impact magnesium plasma level and in some studies magnesium, was not administered concurrently with stimulants [76,79]. Since kidney and liver functions are associated with magnesium level, healthy kidney and liver functions need to be included as well. Liver and renal functions were normal in our control and both ADHD and ASD group. 


\section{Conclusion}

Ferritin level showed significant decrease in our sample of 5-18 years old children with ASD and/or ADHD which would favour examining the level of this element in those groups of children as early as possible; however, extended studies are warranted with randomized controlled trials to prove the role of ferritin as an interventional factor. The results of this pilot trial should be considered with caution for zinc and magnesium but provide a rationale for larger and multisite trials assessing the effectiveness of these elements for children with ADHD and/or ASD.

\section{Clinical Significance}

Recent investigations on neurobiology and treatment of Attention

\section{References}

1 Biederman J, Fitzgerald M, Spencer TJ, Bhide PG, McCarthy DM, et al. (2017) Is paternal smoking at conception a risk for ADHD? A controlled study in youth with and without ADHD. J Atten Disord 1: 1087054717690809.

2 Oner O, Alkar OY, Oner P (2008) Relation of ferritin levels with symptom ratings and cognitive performance in children with attention deficit-hyperactivity disorder. Pediatr Int 50: 40-44.

3 American Psychiatric Association (2013) Diagnostic and statistical manual of mental disorders. $5^{\text {th }}$ edn. Text Revision.

4 Biederman J (2005) Attention-deficit/hyperactivity disorder: A selective overview. Biol Psychiatry 57: 1215-1220.

5 Todd RD, Joyner CA, Ji TH, Sun L, Reich W, et al. (2004) Attentiondeficit/hyperactivity disorder, Tourette's syndrome and restless legs syndrome: The iron hypothesis. Mol Psychiatry 9: 260-263.

6 Konofal E, Lecendreux M, Deron J, Marchand M, Cortese S, et al. (2008) Effects of iron supplementation on attention deficit hyperactivity disorder in children. Pediatr Neurol 38: 20-26.

7 Menegassi M, Mello ED, Guimarães LR, Matte BC, Driemeier F, et al. (2010) Food intake and serum levels of iron in children and adolescents with attention-deficit/hyperactivity disorder. Rev Bras Psiquiatr 32: 132-138.

8 Oner P, Oner O, Azik FM, Cop E, Munir KM (2012) Ferritin and hyperactivity ratings in attention deficit hyperactivity disorder. Pediatr Int 54: 688-692.

9 Sagvolden T (2000) Behavioral validation of the spontaneously hypertensive rat (SHR) as an animal model of attention-deficit/ hyperactivity disorder (ADHD). Neurosci Biobehav Rev 24: 31-39.

10 Pelsser LM, Frankena K, Toorman J, Savelkoul HF, Pereira RR, et al. (2008) A randomized controlled trial into the effects of food on ADHD. Eur Child Adolesc Psychiatry 18: 12-19.

11 Rucklidge J, Johnstone J, Kaplan B (2009) Nutrient supplementation approaches in the treatment of ADHD. Expert Rev Neurother 9: 461-476.

12 Sinn N (2008) Nutrition and dietary influences on attention deficit hyperactivity disorder. Nutr Rev 66: 558-68.

13 Burhans MS, Dailey C, Beard Z, Wiesinger J, Murray-Kolb L, et al. (2005) Iron deficiency: Differential effects on monoamine transporters. Nutr Neurosci 8: 31-38.
Deficit Hyperactivity Disorder (ADHD) and Autism Spectrum Disorder (ASD) have suggested that possible deficiencies of nutrients such as iron, zinc and magnesium could be involved in their etiology. In our study, significantly low serum ferritin level (a marker of iron store) and a trend to decreased serum zinc level have been observed in children affected with ADHD and ASD. The present study raises the question of whether those children should have their serum ferritin and zinc levels checked. A careful dietary history might suggest that the child's intake of iron is deficient and justify the necessary laboratory work to check for tissue deficiency. In documented cases of iron deficiency, clinical common sense may suggest a careful consideration to first replenish iron stores and then re-evaluating before instituting other treatments.

14 Bartolato G, Godar SC, Alzghoul L, Zhang J, Darling RD, et al. (2013 Monoamine oxidase $A$ and $A / B$ knock-out mice display autistic-like features. Int J Neuropsychopharmacol 16: 869-888.

15 Millichap JG, Yee MM, Davidson SI (2006) Serum ferritin in children with attention-deficit hyperactivity disorder. Pediatr Neurol 34: 200-203.

16 Cortese S, Angriman M, Lecendreux M, Konofal E (2012) Iron and attention defi-cit/hyperactivity disorder: What is the empirical evidence so far? A systematic review of the literature. Expert Rev Neurother 12: 1227-1240.

17 Krause J (2008) SPECT and PET of the dopamine transporter in attention-deficit/hyperactivity disorder. Expert Rev Neurother 8: 611-625.

18 Mahmoud MM, El-Mazary AAM, Maher RM, Saber MM (2011) Zinc, ferritin, magnesium and copper in a group of Egyptian children with attention deficit hyperactivity disorder. Ital J Pediatr 37: 60.

19 Parisi P, Villa MP, Donfrancesco R, Miano S, Paolino MC, et al. (2012) Could treatment of iron deficiency both improve ADHD and reduce cardiovascular risk during treatment with ADHD drugs? Med Hypotheses 79: 246-249.

20 Gebril OH, Abdelraouf ER, Hashish AF (2014) A study of zinc, copper and iron parameters in children with cognitive impairment. Med Res J 13: 40-44.

21 Oner O, Oner P, Bozkurt OH, Odabas E, Keser N, et al. (2010) Effects of zinc and ferritin levels on parent and teacher reported symptom scores in attention deficit hyperactivity disorder. Child Psychiatry Hum Dev 41: 441-447.

22 Lepping P, Huber M (2010) Role of zinc in the pathogenesis of attention-deficit hyperactivity disorder. CNS Drugs 24: 721-728.

23 Cardoso CC, Lobato KR, Binfare RW, Ferreira PK, Rosa AO, et al. (2009) Evidence for the involvement of the monoaminergic system in the antide-pressant-like effect of magnesium. Prog Neuropsychopharmacol Biol Psychiatry 33: 235-242.

24 Witkowski M, Hubert J, Mazur A (2011) Methods of assessment of magnesium status in humans: A systematic review. Magnes Res 24: 163-180.

25 Khemakhem AM, Frye RE, El-Ansary A, Al-Ayadhi L, Bacha AB (2017) Novel biomarkers of metabolic dysfunction in autism spectrum disorder: Potential for biological diagnostic markers. Metab Brain Dis 32: 1983-1997. 
26 Cermak SA, Curtin C, Bandini LG (2010) Food selectivity and sensory sensitivity in children with autism spectrum disorders. J Am Diet Assoc 110: 238-246.

27 Halterman JS, Halterman PG (2001) Iron deficiency and cognitive achievement among school-aged children and adolescents in the United States. Pediatrics 107: 1381-1386.

28 Hyman SL, Stewart P, Schmidt B, Cain U, Lemcke N, et al. (2012) Nutrient intake from food in children with autism. Pediatrics 130 : S145-S153.

29 Xia W, Zhou Y, Sun C, Wang J, Wu L (2010) A preliminary study on nutritional status and intake in Chinese children with autism. Eur J Pediatr 169: 1201-1206.

30 Al-Ali SF, Russo S, Alkaissi A (2015) Association between autism spectrum disorder and iron deficiency in children diagnosed autism spectrum disorder in the Northern West Bank. J Health Med Nurs 16: 1-10.

31 Sensi SL, Paoletti P, Koh JY, Aizenman E, Bush Al, et al. (2011) The neurophysiology and pathology of brain zinc. J Neurosci 31:1607616085.

32 Siller SS, Broadie K (2012) Matrix metalloproteinases and minocycline: Therapeutic avenues for fragile $X$ syndrome. Neural Plast 2012: 124548.

33 Bjørklund G (2013) The role of zinc and copper in autism spectrum disorders. Acta Neurobiol Exp (Wars) 73: 225-236.

34 Faber S, Zinn GM, Kern JC, Kingston HM (2009) The plasma zinc/ serum copper ratio as a biomarker in children with autism spectrum disorders. Biomarkers 14: 171-180.

35 Sayehmiri F, Babaknejad N, Bahrami S, Sayehmiri K, Darabi M, et al. (2015) $\mathrm{Zn} / \mathrm{Cu}$ levels in the field of autism disorders: a systematic review and meta-analysis. Iran J Child Neurol 9:1-9.

36 Russo AJ, DeVito R (2011) Analysis of copper and zinc plasma concentration the efficacy of zinc therapy in individuals with Asperger's syndrome, pervasive developmental disorder not otherwise specified (PDD-NOS) and autism. Biomark Insights 6: 127-133.

37 Finegold SM, Downes J, Summanen PH (2012) Microbiology of regressive autism. Anaerobe 18: 260-262.

38 MacFabe DF (2012) Short-chain fatty acid fermentation products of the gut microbiome: Implications in autism spectrum disorders. Microb Ecol Health Dis 23: 19260.

39 Johnson (a) S (2001) Micronutrient accumulation and depletion in schizophrenia, epilepsy, autism and Parkinson's disease? Med Hypotheses 56: 641-645.

40 Johnson (b) S (2001) The multifaceted and widespread pathology of magnesium deficiency. Med Hypotheses 56: 163-170.

41 Nye C, Brice A (2002) Combined vitamin B6-magnesium treatment in autism spectrum disorder. Cochrane Database Syst Rev 4: CD003497.

42 Strambi M, Longini M, Hayek J, Berni S, Macucci F, et al. (2005) Magnesium profile in autism. Biol Trace Elem Res 109: 97-104.

43 Konofal E, Lecendreux M, Arnulf I, Mouren MC (2004) Iron deficiency in children with attention-deficit/hyperactivity disorder. Arch Pediatr Adolesc Med 158: 1113-1115.

44 Chen JR, Hsu SF, Hsu CD, Hwang LH, Yang SC (2004) Dietary patterns and blood fatty acid composition in children with attention-deficit hyperactivity disorder in Taiwan. J Nutr Biochem 15: 467-472.

45 Kiddie JY, Weiss MD, Kitts DD, Levy-Milne R, Wasdell MB (2010)
Nutritional status of children with attention deficit hyperactivity disorder: A pilot study. Int J Pediatr 2010: 767318.

46 Dosman CF, Dermic IE, Brian JA, Senthilselvan A, Harford M, et al. (2006) Ferritin as an indicator of suspected iron deficiency in children with autism spectrum disorder: Prevalence of low serum ferritin concentration. Dev Med Child Neurol 48: 1008-1009.

47 Hergüner S, Keleşoğlu FM, Tanıdır C, Cöpür M (2012) Ferritin and iron levels in children with autistic disorder. Eur J Pediatr 171: 143146.

48 Latif A, Heinz P, Cook R (2002) Iron deficiency in autism and Asperger syndrome. Autism 6: 103-114.

49 Provost B, Crowe TK, Osbourn PL, McClain C, Skipper BJ (2010) Mealtime behaviors of preschool children: comparison of children with autism spectrum disorder and children with typical development. Phys Occup Ther Pediatr 30: 220-233.

50 Beard JL (2008) Why iron deficiency is important in infant development. J Nutr 138: 2534-2536.

51 Uçkardeş Y, Ozmert EN, Unal F, Yurdakök K (2009) Effects of zinc supplementation on parent and teacher behavior rating scores in low socioeconomic level Turkish primary school children. Acta Paediatr 98: 731-736.

52 Pfaender S, Grabrucker AM (2014) Characterization of biometal profiles in neurological disorders. Metallomics 6: 960-977.

53 Lakshmi P, Geetha A (2011) Level of trace elements (copper, zinc, magnesium and selenium) and toxic elements (lead and mercury) in the hair and nail of children with autism. Biol Trace Elem Res 142 148-158.

54 Yasuda H, Tsutsui T (2013) Assessment of infantile mineral imbalances in autism spectrum disorders (ASDs). Int J Environ Res Public Health 10: 6027-6043.

55 Yasuda H, Yoshida K, Yasuda Y, Tsutsui T (2011) Infantile zinc deficiency: Association with autism spectrum disorders. Sci Rep 1: 129.

56 Nakashima AS, Dyck RH (2009) Zinc and cortical plasticity. Brain Res Rev 59: 347-373.

57 Liljeholm M, O'Doherty JP (2012) Contributions of the striatum to learning, motivation, and performance: an associative account. Trends Cogn Sci 16: 467-475.

58 Haber SN (2014) The place of dopamine in the cortico-basal ganglia circuit. Neurosci 282: 248-257.

59 Silberberg G, Bolam JP (2015) Local and afferent synaptic pathways in the striatal micro circuitry. Curr Opin Neurobiol 33: 182-187.

60 Lerner TN, Kreitzer AC (2011) Neuromodulatory control of striatal plasticity and behavior. Curr Opin Neurobiol 21: 322-327.

61 Maloney SE, Rieger MA, Dougherty JD (2013) Identifying essential cell types and circuits in autism spectrum disorders. Int Rev Neurobiol 113: 61-96.

62 Dalley JW, Mar AC, Economidou D, Robbins TW (2008) Neurobehavioral mechanisms of impulsivity: fronto-striatal systems and functional neurochemistry. Pharmacol Biochem Behav 90: 250260.

63 Liu Y, Teeter MM, DuRand CJ, Neve KA (2006) Identification of a $\mathrm{Zn}^{2+}$ binding site on the dopamine D2 receptor. Biochem Biophys Res Commun 339: 873-879.

64 Frederickson CJ, Koh JY, Bush Al (2005) The neurobiology of zinc in health and disease. Nat Rev Neurosci 6: 449-462. 
65 Arnold LE, Pinkham SM, Votolato N (2000) Does zinc moderate essential fatty acid and amphetamine treatment of attention-deficit/ hyperactivity disorder? J Child Adolesc Psychopharmacol 10: 111-117.

66 Rink L, Gabriel P (2000) Iron, magnesium, vitamin D, and zinc deficiencies in children presenting with symptoms of attentiondeficit/hyperactivity disorder. Proc Nutr Soc 59: 541-552.

67 Janusonis S, Anderson GM, Shifrovich I, Rakic P (2006) Ontogeny of brain and blood serotonin levels in 5-HT receptor knockout mice: Potential relevance to the neurobiology of autism. J Neurochem 99: 1019-1031.

68 Shajiband MS, Khan WI (2015) The role of serotonin and its receptors in activation of immune responses and inflammation. Acta Physiol (Oxf) 213: 561-574

69 Takeda A, Hirate M, Tamano H, Oku N (2003) Release of glutamate and GABA in the hippocampus under zinc deficiency. Neurosci Res 72: $537-542$.

70 Schousboe A, Waagepetersen HS (2007) GABA: Homeostatic and pharmacological aspects. Prog Brain Res 160: 9-19.

71 LiQ GM, Xu X, Xiao X, Xu W, Sun X, et al. (2008) Rapid decrease of GAD 67 content before the convulsion induced by hyperbaric oxygen exposure. Neurochem Res 33: 185-193.

72 Mousain-Bosc M, Roche M, Polge A, Pradal-Prat D, Rapin J, et al. (2006) Improvement of neurobehavioral disorders in children supplemented with magnesium-vitamin B6. I. Attention deficit hyperactivity disorders. Magnes Res 19: 46-52.

73 Scassellati C, Bonvicini C, Faraone SV, Gennarelli M (2012). Biomarkers and attention-deficit/hyperactivity disorder: a systematic review and meta-analyses. J Am Acad Child Adolesc Psychiatry 51: 1003-1019.

74 Antalis CJ, Stevens LJ, Campbell M, Pazdro R, Ericson K, et al. (2006) Omega-3 fatty acid status in attention-deficit/hyperactivity disorder. Prostaglandins Leukot Essent Fatty Acids 75: 299-308.

75 Eby GA, Eby KL (2010) Magnesium for treatment-resistant depression: A review and hypothesis. Med Hypotheses 74: 649-660.

76 Mousain-Bosc M, Roche M, Polge A, Pradal-Prat D, Rapin J, et al. (2006) Improvement of neurobehavioral disorders in children supplemented with magnesium-vitamin B6 II. Pervasive developmental disorder-autism. Magnes Res 19: 53-62.

77 D'Amato TJ (2005) Is iron deficiency causative of attention-deficit/ hyperactivity disorder? Arch Pediatr Adolesc Med 159: 788.

78 Donfrancesco R, Parisi P, Vanacore N, Martines F, Sargentini V, et al. (2013) Iron and ADHD: Time to move beyond serum ferritin levels. J Atten Disord 17: 347-357.

79 Huss M, Volp A, Stauss-Grabo M (2010) Supplementation of polyunsaturated fatty acids, magnesium, and zinc in children seeking medical advice for attention-deficit/hyperactivity problems: An observational cohort study. Lipids Health Dis 9: 105. 